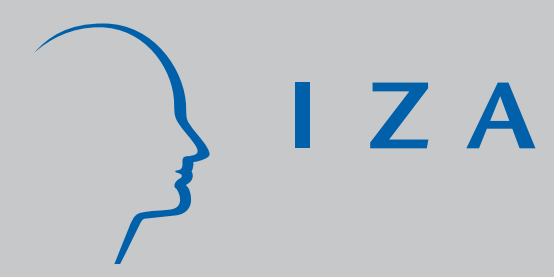

IZA DP No. 1752

Building the Family Nest:

Pre-Marital Investments, Marriage

Markets and Spousal Allocations

Murat lyigun

Randall P. Walsh

September 2005 


\title{
Building the Family Nest: Pre-Marital Investments, Marriage Markets and Spousal Allocations
}

\author{
Murat lyigun \\ University of Colorado, Boulder, \\ Sabanci University, Istanbul \\ and IZA Bonn \\ Randall P. Walsh \\ University of Colorado, Boulder
}

Discussion Paper No. 1752

September 2005

\author{
IZA \\ P.O. Box 7240 \\ 53072 Bonn \\ Germany \\ Phone: +49-228-3894-0 \\ Fax: +49-228-3894-180 \\ Email: iza@iza.org
}

\begin{abstract}
Any opinions expressed here are those of the author(s) and not those of the institute. Research disseminated by IZA may include views on policy, but the institute itself takes no institutional policy positions.

The Institute for the Study of Labor (IZA) in Bonn is a local and virtual international research center and a place of communication between science, politics and business. IZA is an independent nonprofit company supported by Deutsche Post World Net. The center is associated with the University of Bonn and offers a stimulating research environment through its research networks, research support, and visitors and doctoral programs. IZA engages in (i) original and internationally competitive research in all fields of labor economics, (ii) development of policy concepts, and (iii) dissemination of research results and concepts to the interested public.
\end{abstract}

IZA Discussion Papers often represent preliminary work and are circulated to encourage discussion. Citation of such a paper should account for its provisional character. A revised version may be available directly from the author. 


\section{ABSTRACT}

\section{Building the Family Nest: Pre-Marital Investments, Marriage Markets and Spousal Allocations*}

We develop a model of the household in which spousal incomes are determined by premarital investments, the marriage market is characterized by assortative matching, and endogenously-determined sharing rules form the basis of intra-household allocations. By incorporating pre-marital investments and spousal matching into the collective household model, we are able to identify the fundamental determinants of endogenously determined and maritally sustainable intra-marital sharing rules. In particular, we find that all sharing rules along the assortative order support unconditionally efficient outcomes where both pre-marital investments and intra-household allocations are efficient. The efficiency of both pre-marital choices and household allocations then enables us to show that, for each couple, the marriage market generates a unique and maritally sustainable sharing rule that is a function of the distribution of pre-marital endowments and the sex ratios in the market.

JEL Classification: C78, D61, D70

Keywords: collective model, marriage, bargaining, household labor supply

Corresponding author:

Murat lyigun

University of Colorado at Boulder

Department of Economics

Campus Box 256

Boulder, CO 80309-0256

USA

Email: murat.iyigun@colorado.edu

\footnotetext{
* For useful comments and suggestions, we thank Martin Browning, Pierre-Andre Chiappori, Aloysius Siow, and Yoram Weiss as well as seminar participants at the University of Colorado, the University of Copenhagen, 2003 CAM Workshop on the Economics of the Family and the 2004 SED Annual Meeting in Florence.
} 


\section{Introduction}

Recent literature has shown that a treatment of the household as a single decision unit is not consistent with a growing body of empirical evidence on intra-household allocations. ${ }^{1}$ Instead, the "collective" view, in which intra-household allocations are assumed to be efficient and individual members of the family are treated as the core decision-makers, has emerged as a compelling alternative. ${ }^{2}$

The collective household models suggest-and the empirical evidence supports-the notion that relative spousal incomes influence household allocations. ${ }^{3}$ But while the collective approach to household behavior takes spousal incomes as given, these incomes are determined at least in part by decisions individuals make prior to marriage. ${ }^{4}$ Thus, implicit in the construction of the collective framework is the idea that pre-marital investments influence wage earnings and, hence, the intra-marital sharing rules. Nonetheless, due to the lack of an integrated theoretical framework, the empirical studies in this area remain agnostic with respect to the factors that could determine intra-marital allocations.

In this paper, we incorporate pre-marital investments and spousal matching into a "collective" household model where marital matching is assortative and an endogenous sharing rule forms the basis of intra-household allocations. Extending the collective household framework in such fashion enables us to make two contributions to the existing literature. First, we are able to investigate how the intra-marital sharing rules that emerge endogenously in the markets for marriage affect individuals' investment choices prior to household formation. Second, because we show that both pre-marital investments and household allocations are made efficiently (in marriage markets with-

\footnotetext{
${ }^{1}$ See, for example, Browning et al. (1994), Chiappori et al. (2002), and Udry (1996).

${ }^{2}$ The generalized version of this literature was spearheaded by Becker (1981) and developed further by Chiappori $(1988,1992)$.

${ }^{3}$ See, for instance, Browning et al. (1994) and Thomas (1990).

${ }^{4}$ In models of the household where spousal incomes are pure public goods, such decisions can lead to inefficient pre-marital choices and intra-household allocations, although the efficiency of pre-marital investments can be restored as a result of spousal competition in the markets for marriage. For instance, Bergstrom et al. (1986) demonstrate that economic agents under-invest prior to the beginning of a cooperative stage during which their potential partners' incomes are pure public goods. Recently, Peters and Siow (2002) have combined such a model with assortative spousal matching to reveal how competition in large marriage markets restores Pareto efficiency.
} 
out frictions), we are able identify the theoretical determinants of the intra-household sharing rules. ${ }^{5}$

Our main finding is that in many cases a unique sharing rule emerges as a maritally sustainable outcome for each couple. Both the distribution of spousal pre-marital endowments and the sex ratios in the marriage markets help determine sharing rules. However, the role of the sex ratios in determining intra-household allocations increases as the rank of couples in the assortative order rises. That is, for high-ranking couples the intrahousehold allocations are influenced more by the imbalances in the sex ratios, whereas those for lower-ranking couples are influenced more by relative spousal endowments.

\section{Related Literature}

This paper sits at the juncture of three strands in the economics literature. The first strand is on "collective" household models, and early- and late-generation marital bargaining models. These allow for differences between spouses to affect the choices households make by relying on a sharing-rule or an intra-household bargaining mechanism. The common analytical basis of this strand is that family members with potentially different preferences make Pareto-efficient household decisions. Among the earliest examples of the collective models are Becker (1981), Chiappori (1988, 1992), and Bourguignon and Chiappori (1994), and those of exogenous marital bargaining are Manser and Brown (1980), McElroy and Horney (1981), and Sen (1983). Each of these models assume that the sharing rule or the bargaining power of the two sexes are determined exogenously and that couples have different preferences over the choice sets. In two exceptions, Basu (2001) and Iyigun and Walsh (2002) suggest models that treat the bargaining power of the sexes as determined endogenously according to actual relative earnings. Neither of these models, however, examine how the existence of pre-marital investments impacts intra-marital allocations in a collective household setting.

\footnotetext{
${ }^{5}$ Hereafter, we refer to equilibria outcomes as unconditionally Pareto efficient if neither pre-marital investments nor intra-marital allocations can be altered to make one spouse strictly better off while leaving the other no worse off. We define outcomes as conditionally Pareto efficient if, given the choices spouses have made prior to marriage, intra-marital allocations cannot be altered to make one spouse better off while not affecting the other spouse.
} 
The second strand of the literature to which this work is related includes papers that explore how matching influences pre-marital investments in models where spousal incomes are treated as marital public goods. Earlier work in this line, such as Bergstrom, Blume, and Varian (1986), and MacLeod and Malcomson (1993), have shown that the equilibrium level of educational investments are below the Pareto efficient level when pre-marital investments are a public good in marriage. These papers do not take into account how endogenous matching might influence pre-marital investments. Peters and Siow (2002) argue that families make investments in education that are Pareto optimal once marital matching is endogenized. According to their results, in large marriage markets assortative matching and bilateral efficiency together guarantee that the equilibrium distribution of pre-marital investments is efficient. This is due to the fact that, when spousal wealth is a public good in marriage, the competitive marriage market and the assortative matching that occurs within it guide families to indirectly and reciprocally compensate each other for the investments that they make in their own children. Neither of the papers in this strand, including Peters and Siow, address how pre-marital investments might be influenced in a collective household setting.

Our work is most similar to Becker and Murphy (2000) and Browning, Chiappori and Weiss (2003). As far as we know, these two papers and ours represent inaugural attempts to broaden the collective approach to cover aspects of household formation that precede marriage. Becker-Murphy and Browning-Chiappori-Weiss share similarities in that they both merge the collective household model with marital sorting to explore the implications of spousal matching. In both works, however, the endowment each spouse brings to the marriage is taken as given. In contrast, we extend the collective household to include pre-marital investments in order to examine the efficiency implications of pre-marital investments and marital sorting for the collective model. Our motivation in doing so, as we note above, is driven by three facts: One, individuals' pre-marital investments help determine relative spousal incomes, which in turn influence intra-household allocations. Two, allocational efficiency is a central tenet of the standard models of the collective household. And three, incorporating pre-marital investments and marital matching into the collective household model is a crucial step in identifying the 
fundamental determinants of intra-marital sharing rules and their properties.

Finally, it is imperative to note the distinction between the model below, in which spousal matches occur without any frictions (i.e. where all meetings between feasible matches lead to a union), from those like Hadfield (1999), Baker-Jacobsen (2003), and Chiappori-Weiss $(2000,2004)$, in which there exists frictions in the marital matching process (as a result of which not all meetings lead to marriages). While both approaches have their own merits, models with frictions in general sustain inefficient choices. A similar result would attain in a modified version of the model below as well, because in choosing their optimal pre-marital investments, individuals would account for the fact that they might remain single in adulthood. As a result, conditional on the state of being married, couples would invest below the efficient levels. That noted, ex-ante efficiency would still be attained since individuals' choices when young would accurately reflect the uncertainty regarding marriage in the future. This would again make it possible to pin down the determinants of intra-household sharing rules.

The remainder of our paper is organized as follows: In section 3, we present our basic model and discuss the optimal choices of singles. In Section 4, we examine the marital outcomes and their stability conditional on a given set of pre-marital decisions. In Section 5, we discuss individual's pre-marital investments and how the matching process in the marriage markets and the subsequent determination of intra-household allocations influences these investment choices. In Section 6, we establish the properties of the unconditionally Pareto efficient frontier. For each married couple, we then show that sorting in the marriage markets yields a unique sharing rule that is consistent with an allocation on this frontier. In Section 7, we present both an analytical and a numerical example to further illustrate the properties of the unique sharing rules for all matches along the assortative order. In Section 8, we conclude.

\section{The Basic Model}

The economy is made up of individuals who live for two periods. The total mass of women in the economy is equal to $F$ and that of men is equal to $M$. Let $G(N)$ and $H(N)$ respectively be measures of the sets of males and females whose endowments lie in 
the set $N$ and let $r, r \lesseqgtr 1$, denote the measure of women relative to men. ${ }^{6}$ All individuals are endowed with an initial wealth of $y$, where $y \in\left[y^{\min }, y^{\max }\right], y^{\max }>y^{\min } \geq 0$.

When young, individuals allocate their wealth to consumption and a form of investment that augments their future incomes (i.e. education). When they get old, individuals either marry or stay single but they all work and consume. The efficiency units of labor for each individual is linearly proportional to his or her pre-marital investment, $\omega_{i}$.

Individual preferences are defined over first- and second-period consumption, $c_{i}^{1}$ and $c_{i}^{2}$. We assume that preferences of males and females are represented by the following inter-temporal utility function respectively:

$$
U=u_{1}\left(c_{m}^{1}\right)+u_{2}\left(c_{m}^{2}\right)
$$

and

$$
V=v_{1}\left(c_{f}^{1}\right)+v_{2}\left(c_{f}^{2}\right)
$$

where the functions $U$ and $V$ satisfy, $\forall c_{i}^{1}, c_{i}^{2} \in\left[0, y_{i}\right], u^{\prime}, v^{\prime}>0$ and $u^{\prime \prime}, v^{\prime \prime}<0$.

The young invest $\omega_{i}, \omega_{i} \leq y_{i}, i=f, m$, in order to augment their future incomes. ${ }^{7}$ When they get older, individuals can either remain single or match in the marriage market according to their premarital investments $\omega_{i}$. First period investments translate into second period consumption via the production function $h\left(\omega_{m}^{*}, \omega_{f}^{*}\right)$. As Browning, Chiappori and Weiss note, if partners share a public good in marriage, their spousal incomes are complements in marital production. Following their lead, we maintain the assumption of complementarity throughout. We assume that the second period production function $h\left(\omega_{m}^{*}, \omega_{f}^{*}\right)$ is super modular so that $h_{12}\left(\omega_{m}^{*}, \omega_{f}^{*}\right)>0$. Therefore, the marital production function explicitly incorporates gains from marriage and generates assortative matching in the marriage market equilibrium.

\footnotetext{
${ }^{6}$ Hence, $r$ equals one if there are equal measures of men and women and it is less (greater) than one if there are less (more) women than men.

${ }^{7}$ For simplicity, we assume that there are only pecuniary costs of education, although extending the model to allow time costs would not alter our main results.
} 
Let $\omega_{i}^{s}, i=f, m$, denote the optimal investment level of an individual who remains single during adulthood. The second period consumption of a single male is given by $h\left(\omega_{m}^{s}, 0\right)$ and that of a single female is given by $h\left(0, \omega_{f}^{s}\right) .{ }^{8}$ Thus, for single men and women respectively, utility in the second period of life equals

$$
u_{2}\left[h\left(\omega_{m}^{s}, 0\right)\right] \quad \text { and } \quad v_{2}\left[h\left(0, \omega_{f}^{s}\right)\right]
$$

For those individuals who remain single, optimal levels of pre-marital investment, $\omega_{i}^{s}, i=f, m$, are

$$
\omega_{i}^{s}= \begin{cases}\arg \max U=u_{1}\left(y_{m}-\omega_{m}^{s}\right)+u_{2}\left[h\left(\omega_{m}^{s}, 0\right)\right] & \text { if } i=m, \\ \arg \max V=v_{1}\left(y_{f}-\omega_{f}^{s}\right)+v_{2}\left[h\left(0, \omega_{f}^{s}\right)\right] & \text { if } i=f .\end{cases}
$$

The optimal investment levels of single men and women respectively satisfy

$$
u_{1}^{\prime}\left(y_{m}-\omega_{m}^{s}\right)=u_{2}^{\prime}\left[h\left(\omega_{m}^{s}, 0\right)\right] h_{\omega_{m}}\left(\omega_{m}^{s}, 0\right) \quad \text { and } \quad v_{1}^{\prime}\left(y_{f}-\omega_{f}^{s}\right)=v_{2}^{\prime}\left[h\left(0, \omega_{f}^{s}\right)\right] h_{\omega_{f}}\left(0, \omega_{f}^{s}\right) \text {. }
$$

\section{Stable Marital Matchings and Conditional Efficiency}

We now turn to the outcomes in the marriage market, taking first period investment decisions as given. First consider the marriage market outcomes conditional on firstperiod investment choices. Let the pair $\left(\omega_{m}^{*}, \omega_{f}^{*}\right)$, where $\omega_{i}^{*} \in\left[\Omega_{i}^{\min }, \Omega_{i}^{\max }\right], i=f$, $m$, respectively represent a given set of pre-marital investments made by a male and a female. ${ }^{9}$ Let $\hat{G}(N)$ and $\hat{H}(N)$ respectively be measures of the sets of males and

\footnotetext{
${ }^{8}$ The supermodularity of the marital production function imples that, $\forall \omega_{i}>0, i=f, m, h\left(0, \omega_{f}\right)$, $h\left(\omega_{m}, 0\right)<h\left(\omega_{m}, \omega_{f}\right), h_{\omega_{f}}\left(0, \omega_{f}\right)<h_{\omega_{f}}\left(\omega_{m}, \omega_{f}\right)$ and $h_{\omega_{m}}\left(\omega_{m}, 0\right)<h_{\omega_{m}}\left(\omega_{m}, \omega_{f}\right)$.

${ }^{9}$ Note that the endogenously-determined upper and lower bounds of the support of $\omega_{i}$ across all individuals (married or single), which equal $\Omega_{i}^{\min }$ and $\Omega_{i}^{\max }$, increase with the lower and upper bound of the support of the endowments, which equal $y^{\min }$ and $y^{\max }$.
} 
females whose pre-marital investments lie in the set $N$. Conditional on the set of premarital investments, $\left(\omega_{m}^{*}, \omega_{f}^{*}\right)$, the sharing rule that divides second period consumption, $h\left(\omega_{m}^{*}, \omega_{f}^{*}\right)$, between the couple and supports a stable assignment in the marriage market must be such that the utilities achieved by the partners satisfy

$$
c_{m}^{2}\left(\omega_{m}^{*}\right)+c_{f}^{2}\left(\omega_{f}^{*}\right) \geq h\left(\omega_{m}^{*}, \omega_{f}^{*}\right)+g, \quad g>0,
$$

where $g, g>0$, represents a common gain from marriage that is unrelated to spousal incomes and-given that incomes are dependent on investments-to pre-marital choices and where $c_{i}^{2}\left(\omega_{i}^{*}\right), i=f, m$, denotes the second-period consumption offered to an individual with investment $\omega_{i}^{*}$ by a potential partner with $\omega_{-i}^{*}$. Note that equation (6) holds as a strict equality for couples that match with each other in the marriage market and as a strict inequality for couples who do not to match with each other. ${ }^{10}$ Due to the super modularity of the marital output function, note also that, $\forall\left(\omega_{m}^{*}, \omega_{f}^{*}\right)>>0, h\left(0, \omega_{f}^{*}\right)+$ $h\left(\omega_{m}^{*}, 0\right)<h\left(\omega_{m}^{*}, \omega_{f}^{*}\right)$. Therefore, the function $h\left(\omega_{m}, \omega_{f}\right)$ explicitly incorporates "gains" from marriage.

Now, conditional on first period investment levels, let us formally define the marriage market equilibrium. The allocations in marriage, $c_{m}^{2}\left(\omega_{m}^{*}\right)$ and $c_{f}^{2}\left(\omega_{f}^{*}\right)$, define a marriage market equilibrium if for all pairs $\left(\omega_{m}^{*}, \omega_{f}^{*}\right)$ in the set of married couples

1. $1-\hat{G}\left(\omega_{m}^{*}\right)=r\left[1-\hat{H}\left(\omega_{f}^{*}\right)\right]$;

2. $\forall \omega_{m}^{*} \in\left[\Omega_{m}^{\min }, \Omega_{m}^{\max }\right], c_{m}^{2}\left(\omega_{m}^{*}\right)=g+\arg \max _{\omega_{f}^{*}}\left[h\left(\omega_{m}^{*}, \omega_{f}^{*}\right)-c_{f}^{2}\left(\omega_{f}^{*}\right)\right] ;$

3. $\forall \omega_{f}^{*} \in\left[\Omega_{f}^{\min }, \Omega_{f}^{\max }\right], c_{f}^{2}\left(\omega_{f}^{*}\right)=g+\arg \max _{\omega_{m}^{*}}\left[h\left(\omega_{m}^{*}, \omega_{f}^{*}\right)-c_{m}^{2}\left(\omega_{m}^{*}\right)\right]$.

Part 1 of the definition is the marriage market-clearing condition. It guarantees that, by assortative matching, each husband that invests $\omega_{m}^{*}$ or more will be able to match with a spouse who invests $\omega_{f}^{*}$. Thus, we have the following spousal matching functions:

\footnotetext{
${ }^{10}$ The development here follows that of Browning Chiappori and Weiss (2003).
} 


$$
\omega_{m}^{*}=\Phi\left\{1-r\left(1-\hat{H}\left(\omega_{f}^{*}\right)\right]\right\} \equiv \phi\left(\omega_{f}^{*}\right)
$$

and,

$$
\omega_{f}^{*}=\Psi\left\{1-\frac{1}{r}\left(1-\hat{G}\left(\omega_{m}^{*}\right)\right]\right\} \equiv \psi\left(\omega_{m}^{*}\right)
$$

where $\Phi \equiv \hat{G}^{-1}$ and $\Psi \equiv \hat{H}^{-1}$. Note that either of the functions $\phi\left(\omega_{f}^{*}\right)$ and $\psi\left(\omega_{m}^{*}\right)$ fully describe the nature of spousal matching.

Parts 2 and 3 of the definition indicate that all individuals choose their spouses optimally in order to maximize their gains from marriage and as implied by equation (6). Accordingly, these two conditions yield the following two first-order conditions: ${ }^{11}$

$$
c_{m}^{2}\left(\omega_{m}^{*}\right)^{\prime}=h_{\omega_{m}^{*}}\left[\omega_{m}^{*}, \psi\left(\omega_{m}^{*}\right)\right],
$$

and,

$$
c_{f}^{2}\left(\omega_{f}^{*}\right)^{\prime}=h_{\omega_{f}^{*}}\left[\phi\left(\omega_{f}^{*}\right), \omega_{f}^{*}\right] .
$$

In Figure 1, we depict two possible equilibria that could emerge in the marriage market conditional on the investments chosen in the first period. The pre-marital investment levels of the women are shown on the horizontal axis and those of the men are on the vertical axis. The two upward-sloping dashed lines represent two different equilibrium matching functions $\phi\left(\omega_{f}^{*}\right)$. The upward convex curves are the indifference curves of the wives and those that are convex downward are the indifference curves of the husbands and incorporate the sharing rules associated with each potential spousal match. Due to the assortative matching equilibrium, couples for whom the husband has higher initial endowment, $y_{m}$, invest more than those for whom the husband has a lower initial endowment. If distributional factors favor men more than they do women,

\footnotetext{
${ }^{11}$ Note that we express the first-order conditions after applying the envelope theorem.
} 
then the equilibrium matching function will tend to shift to the right leading to more investment by the wives and less by the husbands.

[Figure 1 about here.]

Equations (9) and (10) characterize the sharing rules that hold in equilibrium. The key point is that the second period consumption of each spouse in marriage changes according to not who (s)he marries but based on the marginal contribution the spouse makes to marital output. Note that (9) and (10) hold for all married couples along the assortative order.

To derive the intra-marital allocations of each spouse along the assortative marital order, we integrate the expressions in (9) and (10):

$$
c_{m}^{2}\left(\omega_{m}^{*}\right)=k+\int_{\omega_{m}^{0}}^{\omega_{m}^{*}} h_{\omega_{m}^{*}}[s, \psi(s)] d s .
$$

and,

$$
c_{f}^{2}\left(\omega_{f}^{*}\right)=k^{\prime}+\int_{\omega_{f}^{0}}^{\omega_{f}^{*}} h_{\omega_{f}^{*}}[\phi(t), t] d t .
$$

where $k+k^{\prime}=g+h\left(\omega_{m}^{0}, \omega_{f}^{0}\right)$ and where $\omega_{i}^{0}$ represents the investment level of the lowestranked individual of type $i$ who matches in the marriage market. Note that, for a couple that is in the lowest assortative order, it has to be the case that $k=h\left(\omega_{m}^{s}, 0\right)$ if $r<$ 1 and $k^{\prime}=h\left(0, \omega_{f}^{s}\right)$ if $r>1$. Finally, if $r=1$ multiple equilibria are possible and all we can say is that $k+k^{\prime}=h\left(\omega_{m}^{s}, \omega_{f}^{s}\right)+g .{ }^{12}$ Essentially, these allocations ensure that, when the sex ratio is not balanced (i.e., $r \neq 1$ ), spouses in the lowest assortative order invest as they would if they were single and the spouse from the overabundant group receives his or her reservation level of utility, which is given by equation (4).

We now address how individuals choose their pre-marital investment levels and

\footnotetext{
${ }^{12}$ Note however that when $r=1$ and $g=0$, if the lower bound on investment for each sex is zero, then there is a unique equilibrium where $k=k^{\prime}=0$.
} 
establish the properties of pre-marital investments and intra-household allocations that are maritally sustainable.

\section{Pre-Marital Investments}

We now consider marriage market outcomes with endogenous investment decisions. In equilibrium, males and females choose their levels of pre-marital investments according to

$$
\max _{\omega_{m}} U=u_{1}\left(y_{m}-\omega_{m}\right)+u_{2}\left[c_{m}^{2}\left(\omega_{m}\right)\right]
$$

subject to equation (11), and

$$
\max _{\omega_{f}} V=v_{1}\left(y_{f}-\omega_{f}\right)+v_{2}\left[c_{f}^{2}\left(\omega_{f}\right)\right]
$$

subject to equation (12).

The solution to these problems yield the following two first-order conditions, respectively: 13

$$
u_{1}^{\prime}\left(y_{m}-\omega_{m}^{*}\right)=u_{2}^{\prime}\left[c_{m}^{2}\left(\omega_{m}^{*}\right)\right] h_{\omega_{m}^{*}}\left[\omega_{m}^{*}, \psi\left(\omega_{m}^{*}\right)\right]
$$

and,

\footnotetext{
${ }^{13}$ Implicit in our model and the derivations of the first-order conditions below is the assumption that individuals have no access to capital markets (and therefore that pre-marital investments are selffinanced). The alternative is to assume full access to capital markets in human capital investments (see Becker, 1988, pg. 92-94, for a discussion of the importance and interpretation of credit market imperfections in human capital acquisition). Our main results would go through under this alternative, although equations (15) and (16) would have to be modified so as to equate the marginal return of pre-marital spousal investments to the interest rate paid on educational loans. Then, spousal material endowments would play no role in optimal education decisions but ability endowments-which would determine the rates of return from education-would.
} 


$$
v_{1}^{\prime}\left(y_{f}-\omega_{f}^{*}\right)=v_{2}^{\prime}\left[c_{f}^{2}\left(\omega_{f}^{*}\right)\right] h_{\omega_{f}^{*}}\left[\phi\left(\omega_{f}^{*}\right), \omega_{f}^{*}\right] .
$$

For the marriage market outcomes to be stable, the chosen pre-marital investment levels must satisfy an intertemporal stability condition. That is, it has to be the case that the pre-marital investment levels of married men and women are greater than or equal to those of single men and women with identical levels of endowment, $\omega_{i}^{*} \geq \omega_{i}^{s}$, $i=f, m$. Otherwise, the marital matchings in the lowest assortative order cannot be maintained as the scarce-gender spouses of the lowest assortative rank would prefer to divorce their spouses and marry excess-gender single individuals with higher levels of investment. The super modularity of the marital output function (which implies that $\left.h_{12}\left(\omega_{m}, \omega_{f}\right)>0\right)$ ensures that the intertemporal stability condition is met so that $\omega_{i}^{*} \geq$ $\omega_{i}^{s}, i=f, m$.

Extending the definition above, we formally define the marriage market equilibrium when individuals choose their pre-marital investments optimally. The investments $w_{m}^{*}\left(y_{m}\right)$ and $w_{f}^{*}\left(y_{f}\right)$ and allocations in marriage, $c_{m}^{2}\left[\omega_{m}^{*}\left(y_{m}\right)\right]$ and $c_{f}^{2}\left[\omega_{f}^{*}\left(y_{f}\right)\right]$, define a marriage market equilibrium if there exist endowments, $y_{m}$ and $y_{f}$, for individuals in $F$ and $M$, respectively, such that

1. $1-\hat{G}\left(\omega_{m}^{*}\left(y_{m}\right)\right)=r\left[1-\hat{H}\left(\omega_{f}^{*}\left(y_{f}\right)\right)\right]$

2. $\forall \omega_{m}^{*}\left(y_{m}\right) \in\left[\Omega_{m}^{\min }, \Omega_{m}^{\max }\right], c_{m}^{2}\left(\omega_{m}^{*}\left(y_{m}\right)\right)=g+\arg \max _{\omega_{f}^{*}}\left[h\left(\omega_{m}^{*}\left(y_{m}\right), \omega_{f}^{*}\left(y_{f}\right)\right)-c_{f}^{2}\left(\omega_{f}^{*}\left(y_{f}\right)\right)\right]$;

3. $\forall \omega_{f}^{*}\left(y_{f}\right) \in\left[\Omega_{f}^{\min }, \Omega_{f}^{\max }\right], c_{f}^{2}\left(\omega_{f}^{*}\left(y_{f}\right)\right)=g+\arg \max _{\omega_{m}^{*}}\left[h\left(\omega_{m}^{*}\left(y_{m}\right), \omega_{f}^{*}\left(y_{f}\right)\right)-c_{m}^{2}\left(\omega_{m}^{*}\left(y_{m}\right)\right)\right]$;

4. Investments and consumption decisions satisfy the first order conditions of equations (15) and (16).

In Figure 2, we depict two marital contract curves drawn for two different matching functions, $\phi\left[\omega_{f}\left(y_{f}\right)\right]$. As shown, a more favorable match for the wives raises their intramarital allocations, lowers their pre-marital investments and rotates the equilibrium combinations of pre-marital investments clockwise. 
[Figure 2 about here.]

\section{Pareto Efficient Pre-Marital Investments and Intra-Household Allocations}

For a given couple, the set of unconditionally efficient pre-marital investments and intrahousehold allocations can be determined by solving the following maximization problem:

$$
\max _{\left\{\omega f, \omega_{m}, c_{f}^{2}, c_{m}^{2}\right\}} U=u_{1}\left(y_{m}-\omega_{m}\right)+u_{2}\left(c_{m}^{2}\right)
$$

subject to:

$$
\begin{gathered}
V=v_{1}\left(y_{f}-\omega_{f}\right)+v_{2}\left(c_{f}^{2}\right) \geq \bar{U}_{f}, \\
c_{m}^{2}+c_{f}^{2} \leq h\left(\omega_{m}, \omega_{f}\right)+g
\end{gathered}
$$

and,

$$
\omega_{m} \leq y_{m} \quad \text { and } \quad \omega_{f} \leq y_{f} .
$$

In addition to the constraints of equations (18), (19), and (20), the first-order conditions for this problem are

$$
u_{1}^{\prime}\left(y_{m}-\omega_{m}^{*}\right)=u_{2}^{\prime}\left[c_{m}^{2}\right] h_{\omega_{m}^{*}}\left[\omega_{m}^{*}, \omega_{f}^{*}\right]
$$

and,

$$
v_{1}^{\prime}\left(y_{f}-\omega_{f}^{*}\right)=v_{2}^{\prime}\left[c_{f}^{2}\right] h_{\omega_{f}^{*}}\left[\omega_{m}^{*}, \omega_{f}^{*}\right] .
$$


These conditions can be re-written as in equation (23).

$$
\frac{u_{1}^{\prime}\left(y_{m}-\omega_{m}^{*}\right)-u_{2}^{\prime}\left[c_{m}^{2}\left(\omega_{m}^{*}\right)\right] h_{\omega_{m}^{*}}\left[\omega_{m}^{*}, \psi\left(\omega_{m}^{*}\right)\right]}{u_{2}^{\prime}\left[c_{m}^{2}\left(\omega_{m}^{*}\right)\right]\left\{c_{m}^{2}\left(\omega_{m}^{*}\right)^{\prime}-h_{\omega_{m}^{*}}\left[\omega_{m}^{*}, \psi\left(\omega_{m}^{*}\right)\right]\right\}}=\frac{v_{2}^{\prime}\left[c_{f}^{2}\left(\omega_{f}^{*}\right)\right]\left\{c_{f}^{2}\left(\omega_{f}^{*}\right)^{\prime}-h_{\omega_{f}^{*}}\left[\phi\left(\omega_{f}^{*}\right), \omega_{f}^{*}\right]\right\}}{v_{1}^{\prime}\left(y_{f}-\omega_{f}^{*}\right)-v_{2}^{\prime}\left[c_{f}^{2}\left(\omega_{f}^{*}\right)\right] h_{\omega_{f}^{*}}\left[\phi\left(\omega_{f}^{*}\right), \omega_{f}^{*}\right]} .
$$

Along the Pareto efficient frontier, equation (23) equates the relative marginal utility of pre-marital investments to its disutility. When combined with the endowment constraint, equation (19), the first order conditions of equations (21) and (22) determine the Pareto efficient frontier. Along this frontier, the wife's utility constraint, equation (18), ties down the allocation associated with the wife attaining utility equal to $\bar{U}_{f}$.

If couples make their pre-marital investments efficiently (and given the spousal matching process described in Section 4), then we shall be able to link how intrahousehold allocations are influenced by spousal endowments. To demonstrate the efficiency of the marriage market outcomes requires showing that these outcomes satisfy equations (19)-(22) and thus lie along the Pareto efficient frontier. This is easily done. First, note that the resource constraint of equation (19) is implicit in the construction of the marriage market outcomes. Second, the first order conditions for optimal investment in the marriage market model (equations (15) and (16)) are equivalent to equations (21) and (22). Therefore the marriage market outcomes are unconditionally efficient. ${ }^{14}$

In Figure 3, we illustrate the equilibrium. In it, we super-impose the loci of the Pareto efficient frontier and the reservation utilities on the curve that shows the equilibrium combinations of pre-marital investments, the latter which was originally depicted in Figure 2.

[Figure 3 about here.]

\footnotetext{
${ }^{14}$ Alternatively, note that equation (23) satisfies all the four equations for unconditional efficiency: (9), (10), (15) and (16).
} 
Now we can characterize the equilibrium. The two first-order conditions associated with the optimal pre-marital investments, equations (15) and (16), also implicitly yield two response functions. Let $\omega_{m}=f\left(\omega_{f} ; y_{m}\right)$ and $\omega_{f}=g\left(\omega_{m} ; y_{f}\right)$ respectively represent the implicit association between a male and his potential spouse and between a female and her potential spouse as they are defined by (15) and (16). For a stable marriage market equilibrium, the functions $f\left(\omega_{f} ; y_{m}\right)$ and $g\left(\omega_{m} ; y_{f}\right)$ would be related to the matching functions defined by $\phi\left(\omega_{f}\right)$ and $\psi\left(\omega_{m}\right)$ because, in equilibrium, $\omega_{m}^{*}=\phi\left(\omega_{f}^{*}\right)=$ $f\left(\omega_{f}^{*} ; y_{m}\right)$ and $\omega_{f}^{*}=\psi\left(\omega_{m}^{*}\right)=g\left(\omega_{m}^{*} ; y_{f}\right)$. Put differently, the marital matching functions $\phi\left(\omega_{f}\right)$ and $\psi\left(\omega_{m}\right)$ are such that, $\forall\left(\omega_{m}^{*}, \omega_{f}^{*}\right), \omega_{m}^{*}=\phi\left(\omega_{f}^{*}\right)=f\left(\omega_{f}^{*} ; y_{m}\right)$ and $\omega_{f}^{*}=\psi\left(\omega_{m}^{*}\right)$ $=g\left(\omega_{m}^{*} ; y_{f}\right)$.

\section{Two Examples}

To illustrate our main findings, we now present two examples. In the first one, we provide an analytical solution to a simple specification that enables us to derive closed form solutions. We use this example to verify the main findings we presented above. In our second example, we switch to a more general specification that can only be solved numerically. We use this example to carry out comparative static analyses.

(I) Suppose that the distribution of endowments, $y_{i}, i=f, m$, are uniform on $\left[y^{\min }\right.$, $\left.y^{\max }\right]$ with $y^{\min }>1$. For simplicity, let the marital gain, $g$, equal zero so that $k=k^{\prime}=$ 0 and let the marital production function be given by

$$
h\left(\omega_{m}, \omega_{f}\right)=\left(\omega_{m} \omega_{f}\right)^{1 / 2}
$$

Also suppose that the preferences of males and females are represented by the following inter-temporal utility function respectively:

$$
U=u_{1}\left(c_{m}^{1}\right)+u_{2}\left(c_{m}^{2}\right)=\left(c_{m}^{1}\right)^{1 / 2}+c_{m}^{2}
$$

and 


$$
V=v_{1}\left(c_{f}^{1}\right)+v_{2}\left(c_{f}^{2}\right)=\left(c_{f}^{1}\right)^{1 / 2}+c_{f}^{2},
$$

The first term in each equation respectively corresponds to $u_{1}\left(y_{m}-\omega_{m}\right)$ and $v_{1}\left(y_{f}-\right.$ $\omega_{f}$ ), and the second terms together correspond to equations (11) and (12).

We can now express the consumption shares of husbands and wives during marriage, $c_{m}^{2}\left(\omega_{m}^{*}\right)$ and $c_{f}^{2}\left(\omega_{f}^{*}\right)$, as follows:

$$
c_{m}^{2}=\frac{1}{2} \int_{\omega_{m}^{0}}^{\omega_{m}^{*}}[\psi(s) / s]^{1 / 2} d s,
$$

and,

$$
c_{f}^{2}=\frac{1}{2} \int_{\omega_{f}^{0}}^{\omega_{f}^{*}}[\phi(t) / t]^{1 / 2} d t
$$

where

$$
\omega_{m}^{0} \begin{cases}=\Omega_{m}^{\min } & \text { if } \quad r \geq 1 \\ >\Omega_{m}^{\min } & \text { if } \quad r<1\end{cases}
$$

and,

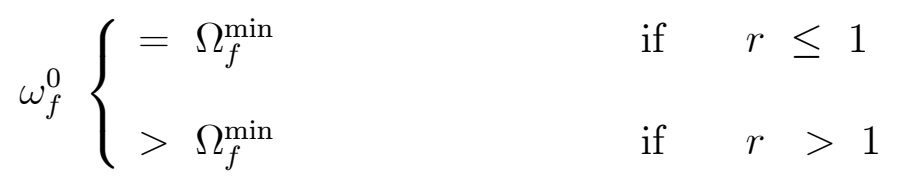

Note that the marriage market matching conditions given by equations (11) and (12) are already embedded in the constructs of (27) and (28). Thus, in order to determine the optimal and efficient levels of pre-marital investments that also yield unconditionally efficient intra-household allocations, we can now maximize (25) and (26) with respect to $\omega_{m}$ and $\omega_{f}$ respectively and subject to equations (27) and (28). The first-order conditions associated with this problem are given by the following: 


$$
\frac{1}{\left(y_{m}-\omega_{m}^{*}\right)^{1 / 2}}=\left[\frac{\psi\left(\omega_{m}^{*}\right)}{\omega_{m}^{*}}\right]^{1 / 2}=\left(\frac{\omega_{f}^{*}}{\omega_{m}^{*}}\right)^{1 / 2}
$$

and,

$$
\frac{1}{\left(y_{f}-\omega_{f}^{*}\right)^{1 / 2}}=\left[\frac{\phi\left(\omega_{f}^{*}\right)}{\omega_{f}^{*}}\right]^{1 / 2}=\left(\frac{\omega_{m}^{*}}{\omega_{f}^{*}}\right)^{1 / 2}
$$

Using (31) and (32), we can generate two response functions $\omega_{m}=f\left(\omega_{f} ; y_{m}\right)$ and $\omega_{f}=g\left(\omega_{m} ; y_{f}\right)$ as we defined above. These functions are such that, $\forall\left(\omega_{m}^{*}, \omega_{f}^{*}\right)$, they yield the following:

$$
\omega_{m}^{*}=\frac{y_{m} \psi\left(\omega_{m}^{*}\right)}{1+\psi\left(\omega_{m}^{*}\right)}=\frac{y_{m} \omega_{f}^{*}}{1+\omega_{f}^{*}} \quad \text { and } \quad \omega_{f}=\frac{y_{f} \phi\left(\omega_{f}^{*}\right)}{1+\phi\left(\omega_{f}^{*}\right)}=\frac{y_{f} \omega_{m}^{*}}{1+\omega_{m}^{*}}
$$

Using (33) we can solve for the spousal levels of pre-marital investments for each pair in equilibrium, $\left(\omega_{m}^{*}, \omega_{f}^{*}\right)$ :

$$
\omega_{m}^{*}=\frac{y_{m} y_{f}-1}{1+y_{f}} \quad \text { and } \quad \omega_{f}^{*}=\frac{y_{m} y_{f}-1}{1+y_{m}}
$$

Therefore, the uniformity of the endowment distributions over $\left[y^{\min }, y^{\max }\right]$ together with (33) and the marriage market clearing condition, $1-G\left(y_{m}\right)=r\left[1-H\left(y_{f}\right)\right]$, implies the following:

$$
1-\frac{y_{m}-y^{\min }}{y^{\max }-y^{\min }}=r\left(1-\frac{y_{f}-y^{\min }}{y^{\max }-y^{\min }}\right)
$$

We are now in position to establish the properties of the equilibrium distributions of pre-marital investments under three different cases: 
1. If $r=1$ so that the measures of men and women in the marriage market are identical, all individuals would marry. Given equation (34), we can establish that, $\forall\left(\omega_{m}^{*}, \omega_{f}^{*}\right), y_{m}=y_{f}$. As a result, equation (33) implies that

$$
\omega_{m}^{*}=\omega_{f}^{*}=y_{m}-1=y_{f}-1
$$

Hence, we establish that when $r=1$ so that all individuals marry, both spouses' get equal shares of the marital output. That is, $\forall\left(\omega_{m}^{*}, \omega_{f}^{*}\right), y_{m}=y_{f}$ $\Rightarrow \omega_{m}^{*}=\omega_{f}^{*} \Rightarrow u_{1}=v_{1}$.

2. If $r<1$ so that there are fewer women than men in the marriage market, there will be some unmarried men in equilibrium. Using equation (35), we can establish that, $\forall\left(\omega_{m}^{*}, \omega_{f}^{*}\right), y_{m}=(1-r) y^{\max }+r y_{f}$. Accordingly, the endowment of the wife in the lowest assortative rank is equal to $y_{\text {min }}$, but that of her husband equals $(1-r) y^{\max }+r y^{\min }>y^{\min }$.

We can rewrite (34) to determine the endowment matches that emerge in equilibrium, $\forall\left(\omega_{m}^{*}, \omega_{f}^{*}\right)$, when $r<1$ :

$$
\omega_{m}^{*}=\frac{\left[(1-r) y^{\max }+r y_{f}\right] y_{f}-1}{1+y_{f}} \quad \text { and } \quad \omega_{f}^{*}=\frac{\left[(1-r) y^{\max }+r y_{f}\right] y_{f}-1}{1+(1-r) y^{\max }+r y_{f}}
$$

where, by construction, $\forall\left(\omega_{m}^{*}, \omega_{f}^{*}\right), \omega_{m}^{*}>\omega_{f}^{*}$. Hence, we conclude, $\forall\left(\omega_{m}^{*}, \omega_{f}^{*}\right), y_{m}$ $>y_{f} \Rightarrow \omega_{m}^{*}>\omega_{f}^{*} \Rightarrow u_{1}>v_{1}$.

3. If $r>1$ so that there are more women than men in the marriage market, there will be some unmarried women in equilibrium. Again relying on (35) and the uniformity of the endowment distributions over $\left[y^{\min }, y^{\max }\right]$ we can establish that, $\forall\left(\omega_{m}^{*}, \omega_{f}^{*}\right)$, 
$y_{f}=\left[(r-1) y^{\max }+y_{m}\right] / r$. And similar to the case above, the endowment of the husband in the lowest assortative rank is equal to $y_{\min }$, but that of his wife equals $\left[(r-1) y^{\max }+y^{\min }\right] / r>y^{\min }$.

Following the steps above, we can determine the endowment matches that emerge in equilibrium, $\forall\left(\omega_{m}^{*}, \omega_{f}^{*}\right)$, when $r>1$ :

$$
\omega_{m}^{*}=\frac{\left[\frac{(r-1) y^{\max }+y_{m}}{r}\right] y_{m}-1}{1+\frac{(r-1) y^{\max }+y_{m}}{r}} \text { and } \quad \omega_{f}^{*}=\frac{\left[\frac{(r-1) y^{\max }+y_{m}}{r}\right] y_{m}-1}{1+y_{m}}
$$

where, by construction, $\forall\left(\omega_{m}^{*}, \omega_{f}^{*}\right), \omega_{m}^{*}<\omega_{f}^{*}$. Hence, we conclude, $\forall\left(\omega_{m}^{*}, \omega_{f}^{*}\right), y_{m}$ $<y_{f} \Rightarrow \omega_{m}^{*}<\omega_{f}^{*} \Rightarrow u_{1}<v_{1}$.

(II) Next, we turn to a more general specification which, for most cases, cannot be solved analytically. We solve this example computationally and use it to explore the model's general implications with respect to the optimal levels of pre-marital investment, intra-household sharing and the stability of marital sorting.

Suppose that the distribution of endowments, $y_{i}, i=f, m$, are uniform on $[0,1]$. Let the marital production function be given by

$$
h\left(\omega_{m}, \omega_{f}\right)=\frac{\left(\omega_{m}+\omega_{f}\right)^{2}}{2} .
$$

Also suppose that the preferences of males and females are represented by the following inter-temporal utility function respectively:

$$
U=u_{1}\left(c_{m}^{1}\right)+u_{2}\left(c_{m}^{2}\right)=\ln c_{m}^{1}+\ln c_{m}^{2}
$$

and

$$
V=v_{1}\left(c_{f}^{1}\right)+v_{2}\left(c_{f}^{2}\right)=\ln c_{f}^{1}+\ln c_{f}^{2},
$$


As in example (I), the first term in each equation respectively corresponds to $u_{1}\left(y_{m}-\right.$ $\left.\omega_{m}\right)$ and $v_{1}\left(y_{f}-\omega_{f}\right)$, and the second period consumption levels of husbands and wives are respectively given by plugging the assumed form of $h($.$) into equations (11) and (12)$

$$
c_{m}^{2}=k+\int_{\omega_{m}^{0}}^{\omega_{m}^{*}}[s+\psi(s)] d s
$$

and,

$$
c_{f}^{2}=k^{\prime}+\int_{\omega_{f}^{0}}^{\omega_{f}^{*}}[\phi(t)+t] d t
$$

where

$$
\omega_{m}^{0} \begin{cases}=0 & \text { if } \quad r \geq 1 \\ >0 & \text { if } \quad r<1\end{cases}
$$

and,

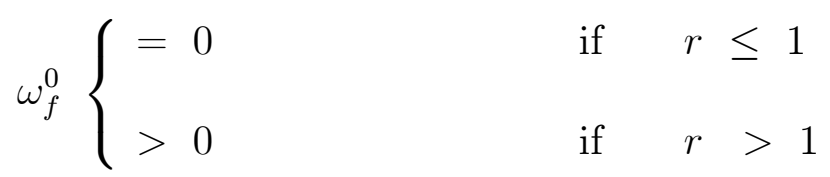

Using this example, we explore (a) the existence of a marriage market equilibrium and (b) how changes in the sex ratios in the marriage markets, $r$, influence this equilibrium. ${ }^{15}$

With respect to the existence of the marital equilibrium, we find in all the exercises we carry out that the marital matching functions $\phi\left(\omega_{f}\right)$ and $\psi\left(\omega_{m}\right)$ are such that, $\forall\left(\omega_{m}^{*}\right.$, $\left.\omega_{f}^{*}\right), \omega_{m}^{*}=\phi\left(\omega_{f}^{*}\right)$ and $\omega_{f}^{*}=\psi\left(\omega_{m}^{*}\right)$. That is, in all specifications, our numerical exercise generates marital matching functions that are consistent with a unique equilibrium in the marriage markets.

Figures 4 through 7 and Table 1 summarize the results of the numerical exercises. Figures 4 and 5 summarize the equilibria when $r=1.25$ and Figures 6 and 7 for when $r=$

\footnotetext{
${ }^{15}$ The Matlab code used in generating the results below are available from the authors upon request.
} 
1.53. Figures 4 and Figure 6 compare consumption and investment behaviors while the four panels of Figures 5 and 7 evaluate the effect of marriage on individual utility. The marital surplus measures presented in panel (c) of these two figures measure the increase in endowment necessary to entice a married individual to relinquish his or her right to be married (Willingness to Accept). In addition to the more interesting asymmetric cases, Table 1 presents results for the symmetric case where $r=1$. In section (a) we present the results for $r=1$, in section (b) we tabulate those for $r=1.25$, and in section (c), the results for $r=1.53$. The table is organized based on the endowment of the wife. For each of the three panels, the wife's percent of the entire endowment, wife's percent of total investment, wife's percent of second period consumption and wife's percent of total surplus (as defined above) are reported.

In the symmetric case in which $r=1$ and all individuals get married, each couple along the assortative order marries such that spouses have identical endowments, pre-marital investments, and intra-household allocation shares. As is shown in Table 1, a higher ratio of women to men in the marriage markets transfers marital gains from women to men-with the effect being most pronounced among the lower assortative ranks. This transfer arises as women compete away their surplus in response to their increased abundance. As shown in the four panels of Figure 5, they partially mitigate this new disadvantage through increased investment but still consume less than men of identical endowment levels in both periods. Moreover, as depicted in the top two panels of Figure 5, all married individuals' utility levels exceed those of singles with identical endowment levels. The exceptions to this observation are the married women in the lowest rank who receive their singles (reservation) utility. Since women in the lowest assortative rank marry men whose endowments are equal to zero and the equilibrium in the marriage markets ensures that all spouses receive the marginal return to their pre-marital investments, the pre-marital investments of married, lowest-rank women equal single women with identical endowment levels. But because women in higher ranks marry men whose endowment levels are more similar to theirs (which raises the wives' marginal return to pre-marital investments), such women invest a relatively higher share of their endowments compared to women in lower ranks. As shown in the last panel of Figure 5, this 
implies that women capture an increasing share of the marital gains as their ranks in the assortative order rises. Finally, compared to the case in which the sex ratio is fully balanced $(r=1)$, the optimal pre-marital investment levels of the more (less) abundant sex increases (decreases) when the sex ratio is not in balance $(r \neq 1)$. In contrast, the optimal second-period consumption levels of the more (less) abundant gender falls (rises) when the sex ratio is not in balance. Both of these observations are due to the fact that a higher share of the marital gains are transferred to the less abundant gender the more unbalanced is the sex ratio. Nonetheless, the impact of an unbalanced sex ratio is stronger in the lower assortative ranks and it dissipates as the rank of a couple rises. In fact, as seen in the last columns of sections (a), (b) and (c), wives' marital surplus-as measured by their willingness to accept to stay married-relative to the total surplus monotonically increases as a couple's marital rank rises. This last observation is quite important with regard to the arguments of intra-household sharing rules: while both the marriage-market sex ratio and relative spousal endowments influence intrahousehold allocations and pre-marital investments, the relative importance of the sex ratio increases and that of relative spousal endowments decreases as the rank of a couple in the assortative order increases.

In Figures 6 and 7 and in section (c) of Table 1 we show the equilibrium choices for $r=1.53$. As can be observed, the general patterns we discussed above are retained in this case as well, although the disparities between the sexes in pre-marital investments, consumption levels, marital gains and intra-household allocation shares are magnified.

[Table 1 about here.]

[Figures 4 through 7 about here.]

\section{Conclusion}

In recent years the "collective" model of the household, in which individual members

of the family are treated as the core decision-makers and a sharing rule generates ef- 
ficient intra-household allocations, has emerged as the most promising framework for understanding household behavior. These models suggest that relative spousal incomes influence household allocations but they do not account for the fact that the household income can be determined at least in part by decisions individuals make prior to marriage. As we point out above, the lack of an integrated theoretical framework-in which the intra-household sharing rules are derived endogenously-accounts for why empirical studies in this area remain agnostic with respect to the factors that could determine intra-marital allocations.

In this paper, we present the first attempt to extend to collective household model to cover pre-marital investments and matching in the marriage markets. Our endeavour shows that, for each couple, an endogenously determined sharing rule emerges as the only maritally sustainable outcome. Both the distribution of spousal pre-marital endowments and the sex ratios in the marriage markets help to determine a marital sharing rule. However, imbalances in the sex ratios become more prominent in influencing intrahousehold as the rank of couples in the assortative order rises. In particular, we find that, for high-ranking couples, the intra-household allocations are affected more by the imbalance in the sex ratios whereas those for lower-ranking couples are influenced more by relative spousal endowments. We also find that all sharing rules along the assortative marital order yield Pareto efficient investment choices and intra-household allocations. 


\section{References}

Baker, M. J. and J. P. Jacobsen. (2003). "Marriage, Specialization, and the Gender Division of Labor," University of Connecticut, unpublished manuscript.

Basu, K. (2001). "Gender and Say: A Model of Household Behavior with EndogenouslyDetermined Balance of Power," Cornell University, unpublished manuscript.

Becker, G. S. (1981). A Treatise on the Family, (MA: Harvard University Press).

Becker, G. S. (1993). Human Capital, (Chicago: The University of Chicago Press).

Becker, G. S. and K. M. Murphy. (2000). Social Economics, (MA: Harvard University Press).

Bergstrom, T. C., L. E. Blume, and H. R. Varian. (1986). "On the Private Provision of Public Goods," Journal of Public Economics, 29, February, 25-49.

Bourguignon, F. and P. Chiappori. (1994). "The Collective Approach to Household Behavior," in R. Blundell, I. Preston, and I. Walker eds., The Measurement of Household Welfare, (Cambridge, U.K.: Cambridge University Press).

Browning, M., F. Bourguignon, P. A. Chiappori, and V. Lechene. (1994). "Income and Outcomes: A Structural Model of Intrahousehold Allocation," Journal of Political Economy, 102 (6), 1067-96.

Browning, M., P. A. Chiappori, and Y. Weiss. (2003). "A Simple Matching Model of the Marriage Market," University of Chicago, unpublished manuscript.

Chiappori, P. A. (1988). "Rational Household Labor Supply," Econometrica, 56, 6390 .

Chiappori, P. A. (1992). "Collective Labor Supply and Welfare," Journal of Political Economy, 100 (3), 437-67.

Chiappori, P. A., B. Fortin, and G. Lacroix. (2002). "Marriage Market, Divorce Legislation, and Household Labor Supply," Journal of Political Economy, 110 (1), 37-72.

Chiappori, P. A. and Y. Weiss. (2000). "Marriage Contracts and Divorce: An Equilibirum Analysis," University of Chicago, unpublished manuscript. 
Chiappori, P. A. and Y. Weiss. (2004). "Divorce, Remarriage and Child Support," Tel Aviv University, unpublished manuscript.

Hadfield, G. K. (1999). "A Coordination Model of the Sexual Division of Labor," Journal of Economic Behavior and Organization, 40 (2), 125-53.

Iyigun, M F. and R. P. Walsh. (2002). "Endogenous Gender Power, Housheold Labor Supply, and the Quantity-Quality Tradeoff," University of Colorado, unpublished manuscript.

MacLeod, W. B. and J. M. Malcomson. (1993). "Investment, Holdup, and the Form of Market Contracts," American Economic Review, 83, September, 811-37.

Manser, M. and M. Brown. (1980). "Marriage and Housheold Decision-Making: A Bargaining Analysis," International Economic Review, 21, February, 31-44.

McElroy, M. B. and M. J. Horney. (1981). "Nash-Bargained Decisions: Towards a Generalization of the Theory of Demand," International Economic Review, 22, June, 333-49.

Peters, M. and A. Siow. (2002). "Competing Pre-Marital Investments," Journal of Political Economy, 110 (3), 592-608.

Sen, A. (1983). "Economics and the Family," Asian Development Review, 1, 14-26.

Udry, C. (1996). "Gender, the Theory of Production, and the Agricultural Household," Journal of Political Economy, 104 (5), October, 1010-46. 
Figure 1: The Marital Matching Function

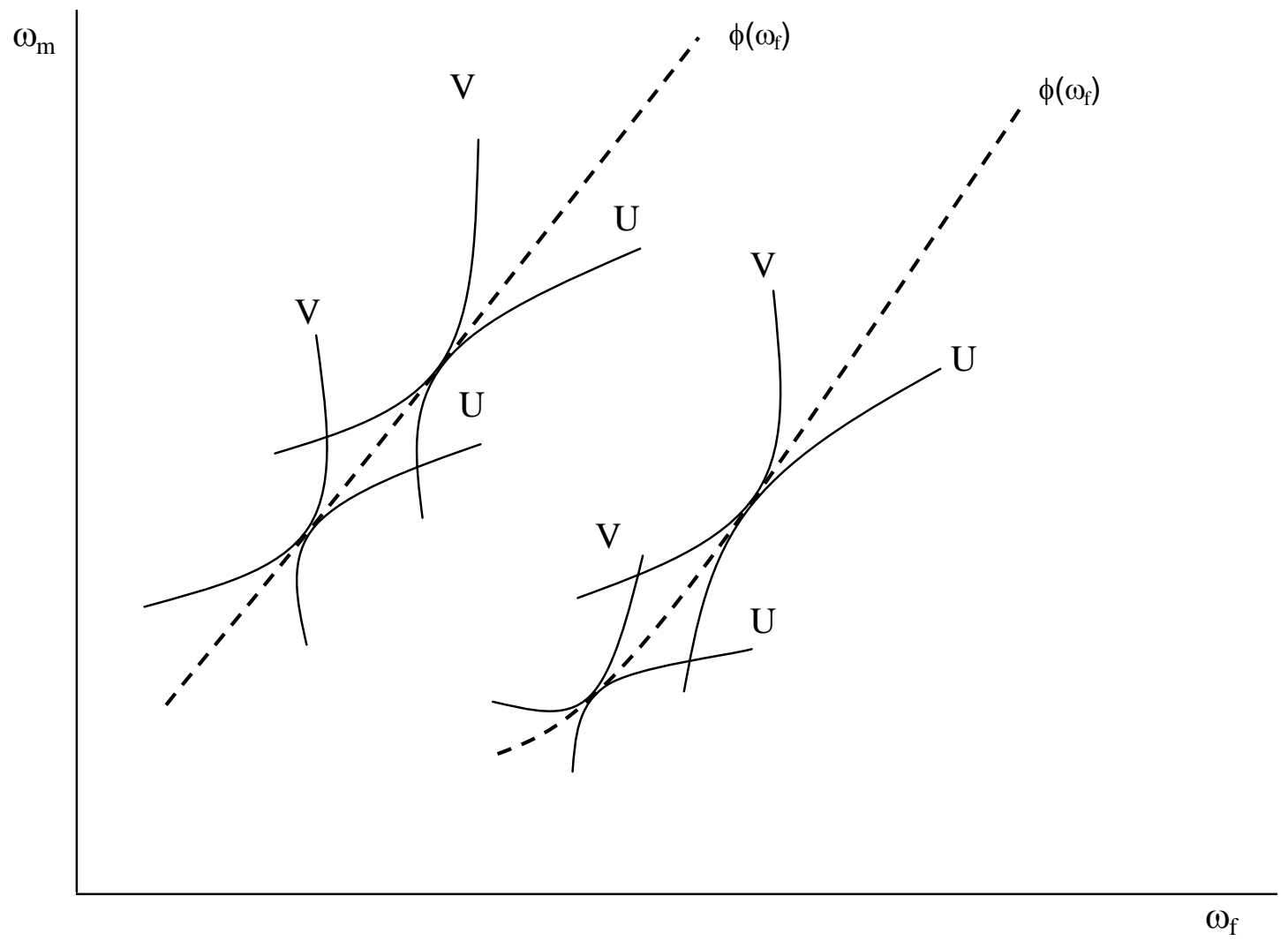


Figure 2: The Marital Contract Curve

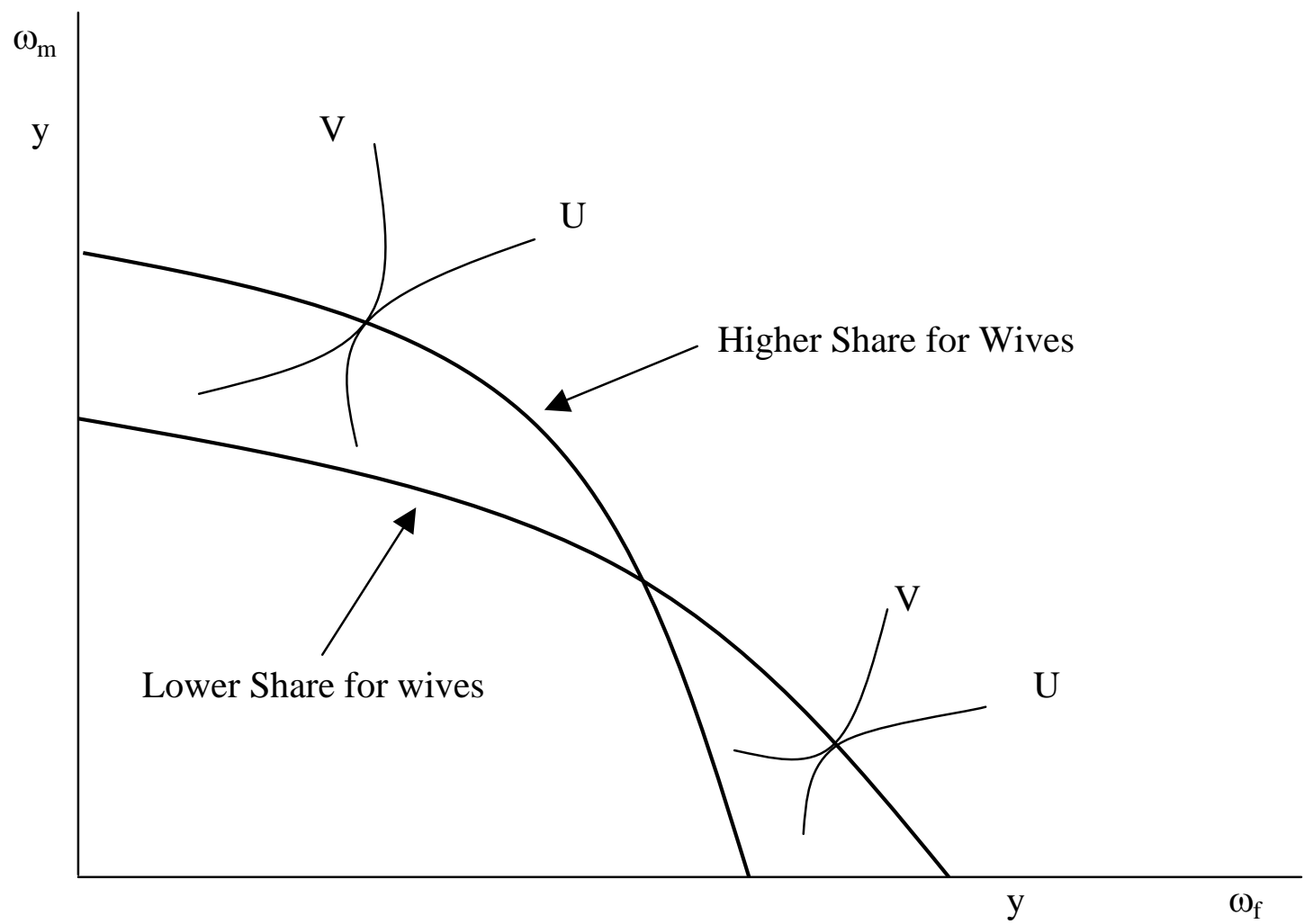


Figure 3: The Marital Contract Curve and the Efficient Frontier

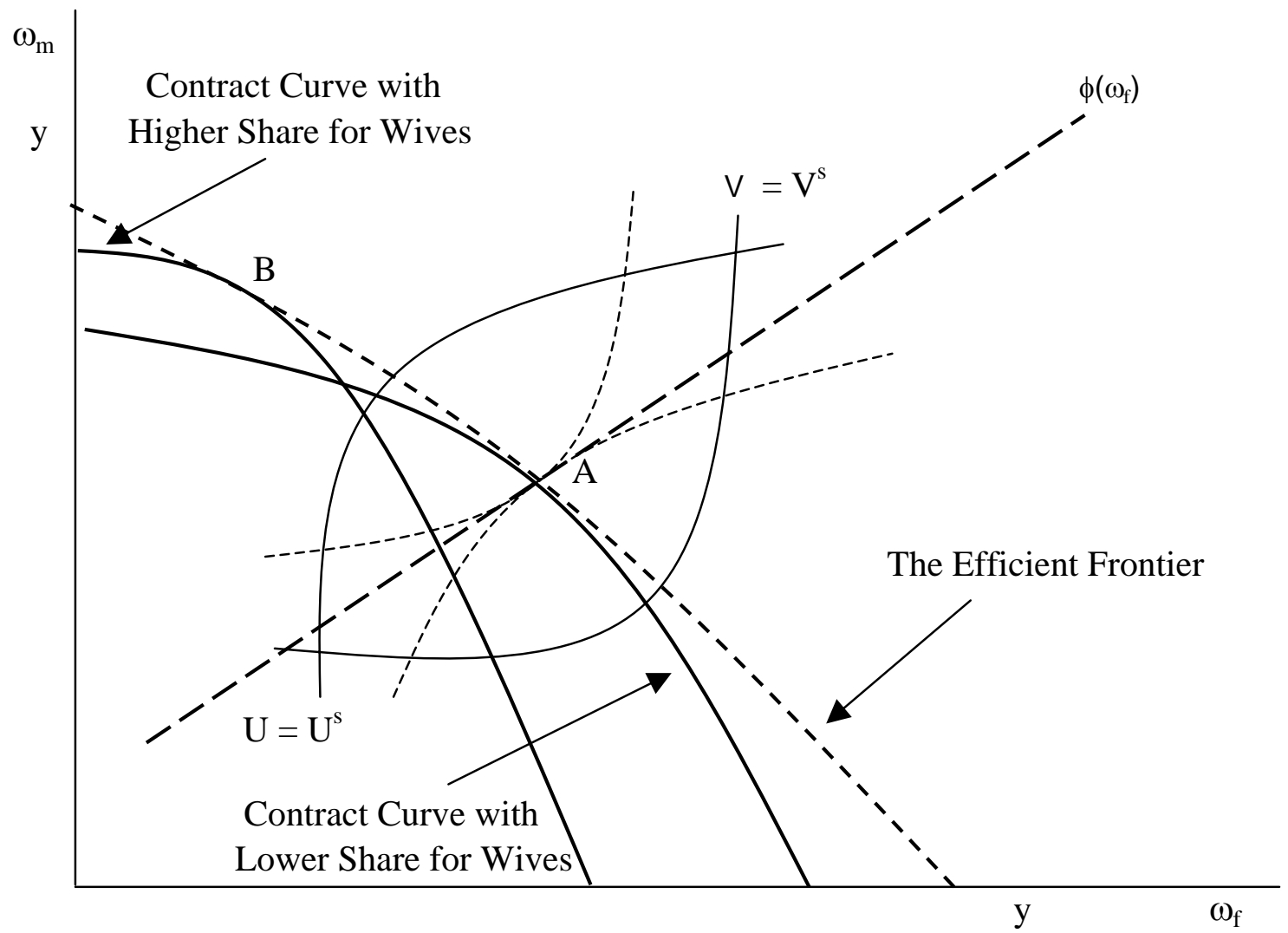


Figure 4: Consumption and Investment, $\mathrm{R}=1.25$

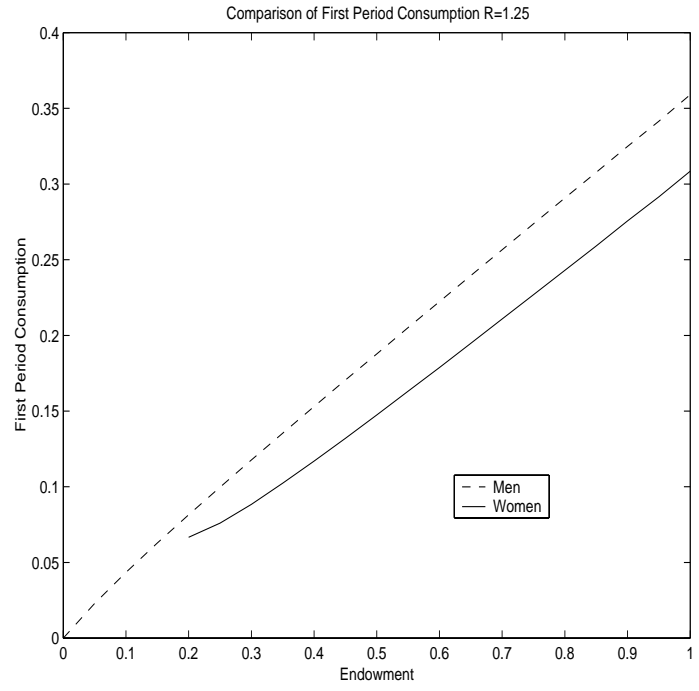

(a) First Period Consumption

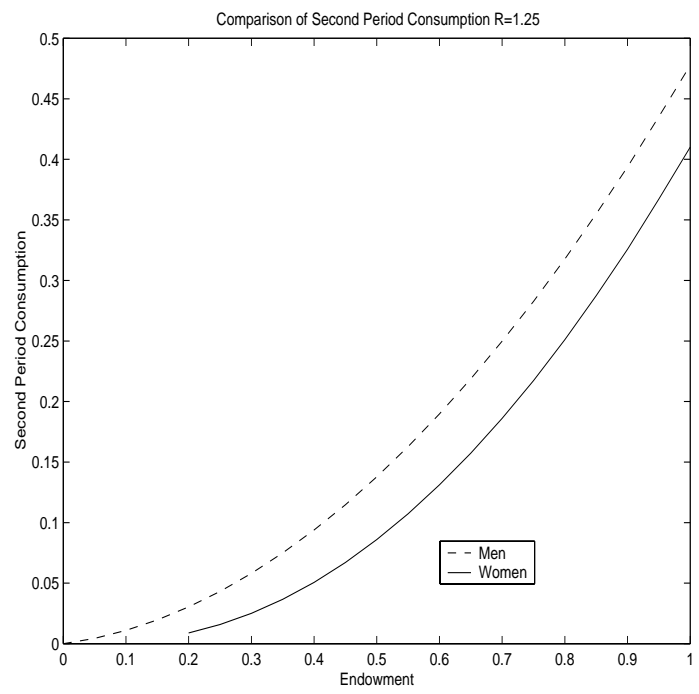

(c) Second Period Consumption

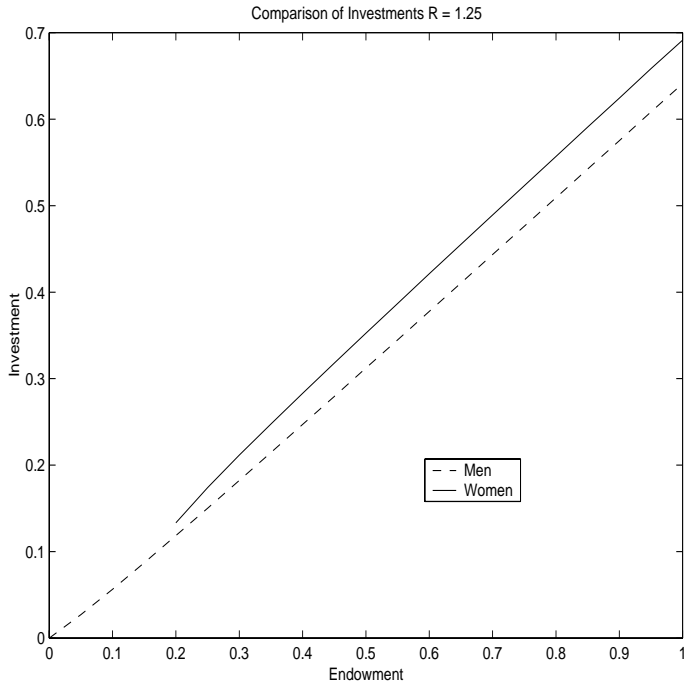

(b) Investment 
Figure 5: Utility and Surplus, $\mathrm{R}=1.25$

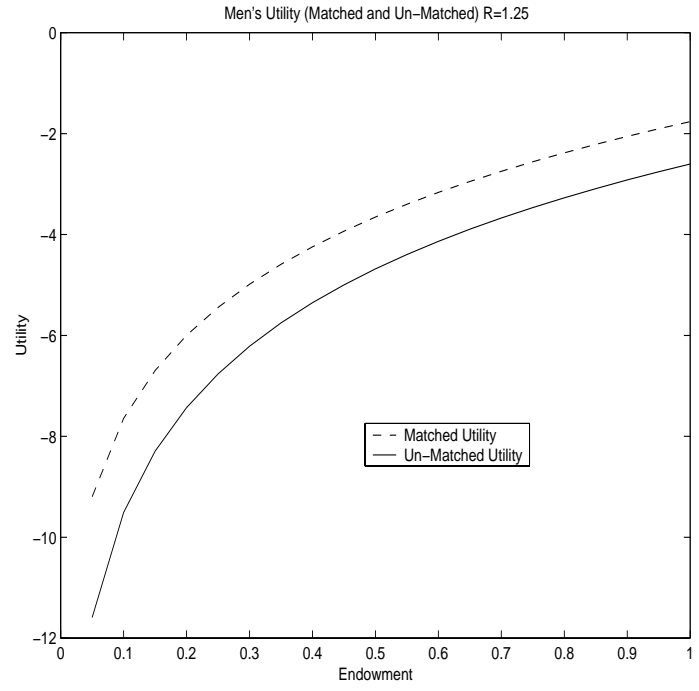

(a) Men's Utility

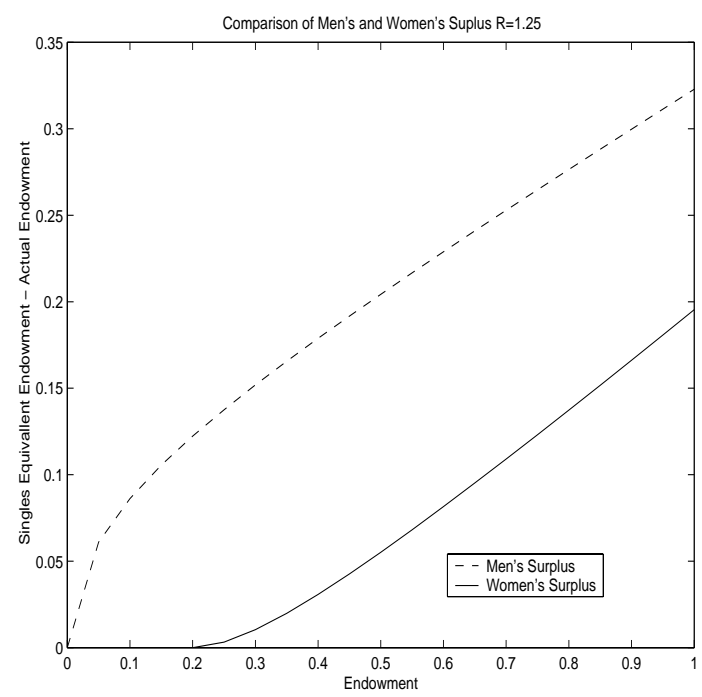

(c) Marital Surplus

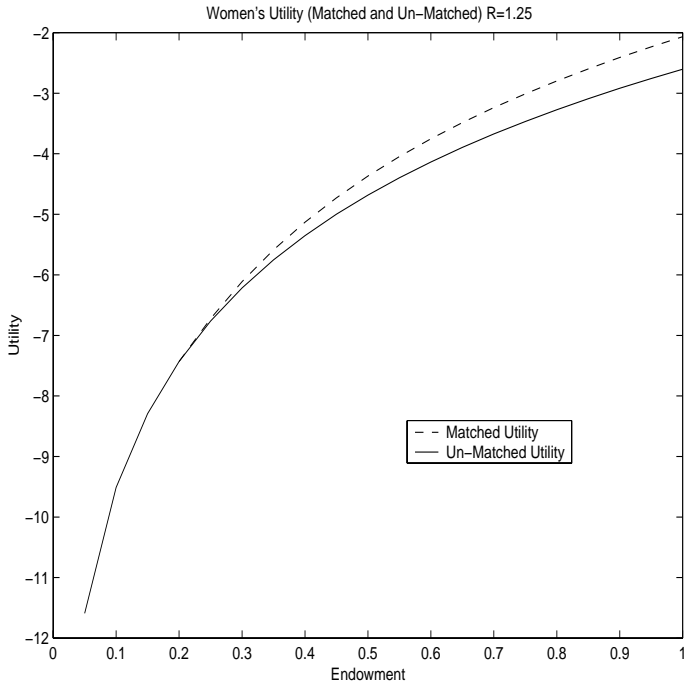

(b) Women's Utility

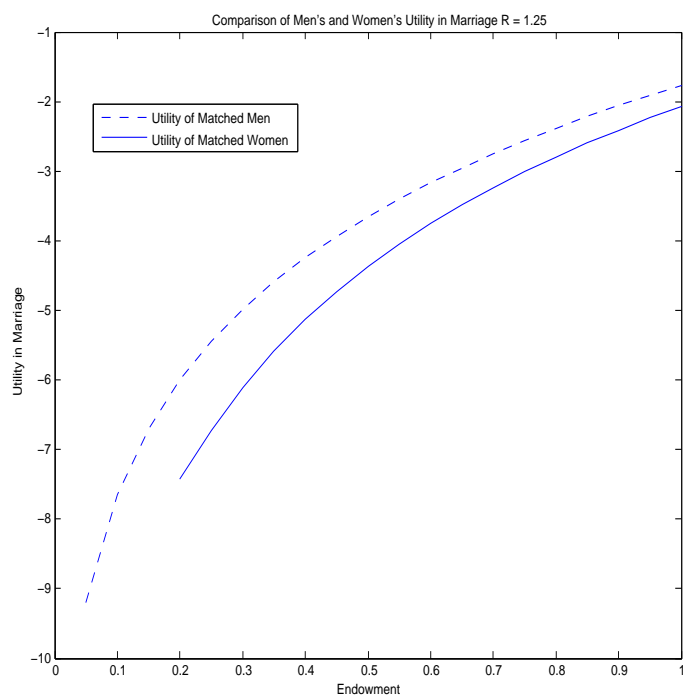

(d) Comparison of Matched Utilities 
Figure 6: Consumption and Investment, $\mathrm{R}=1.53$

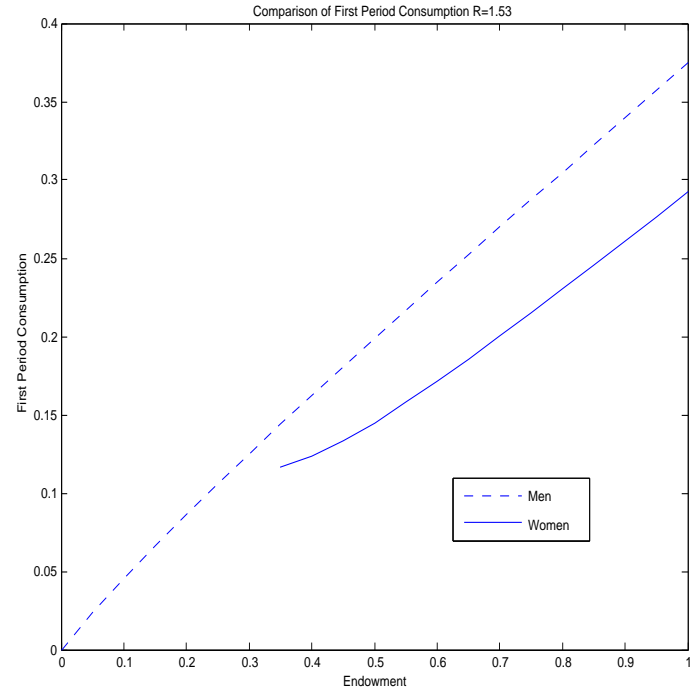

(a) First Period Consumption

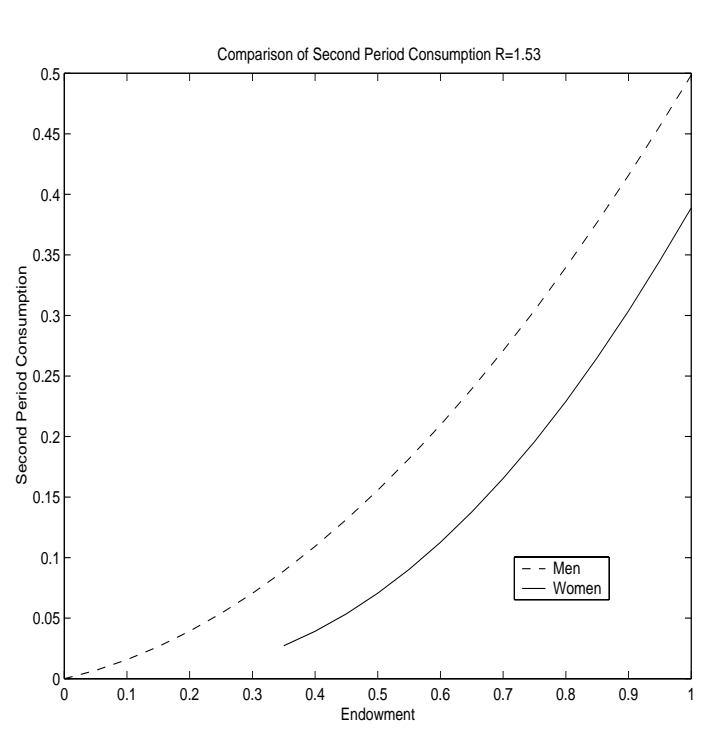

(c) Second Period Consumption

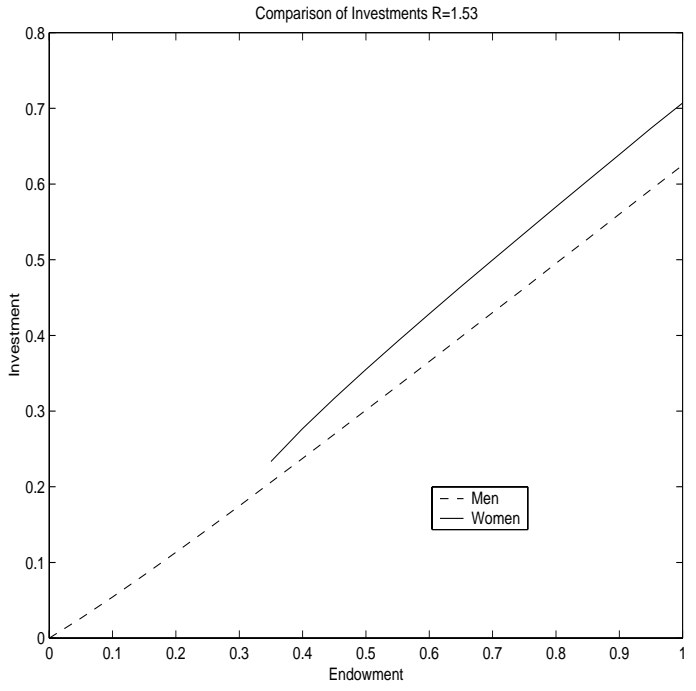

(b) Investment 
Figure 7: Utility and Surplus, $\mathrm{R}=1.53$

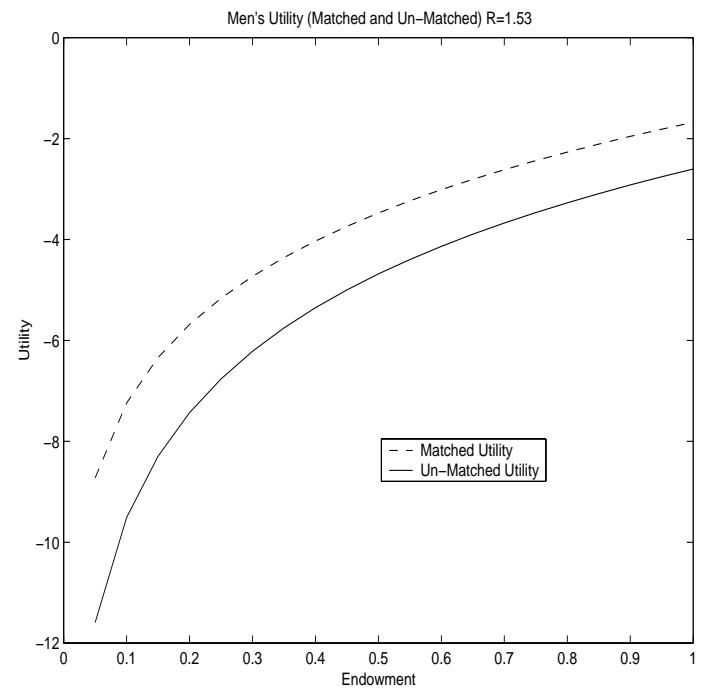

(a) Men's Utility

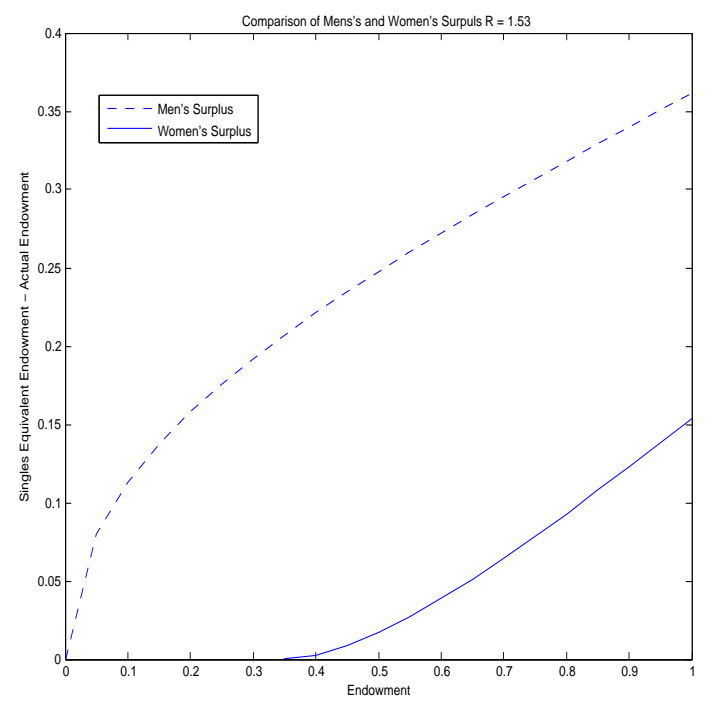

(c) Marital Surplus

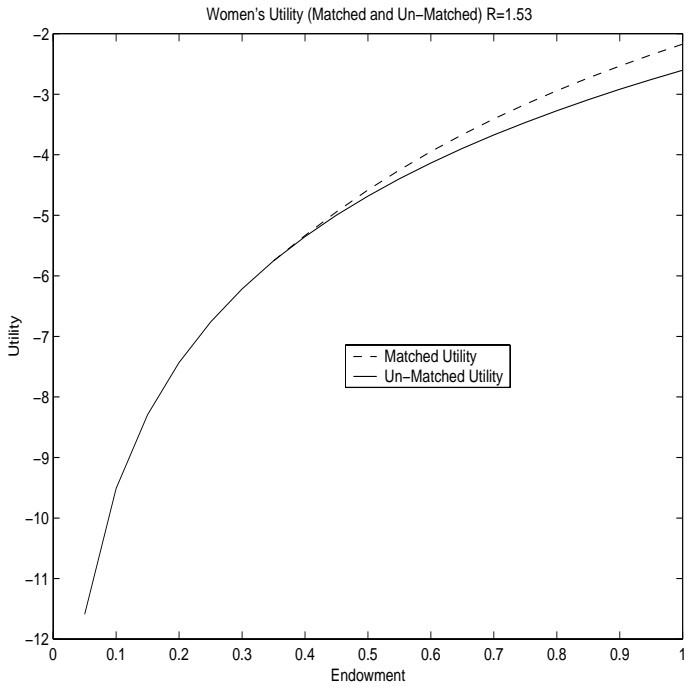

(b) Women's Utility

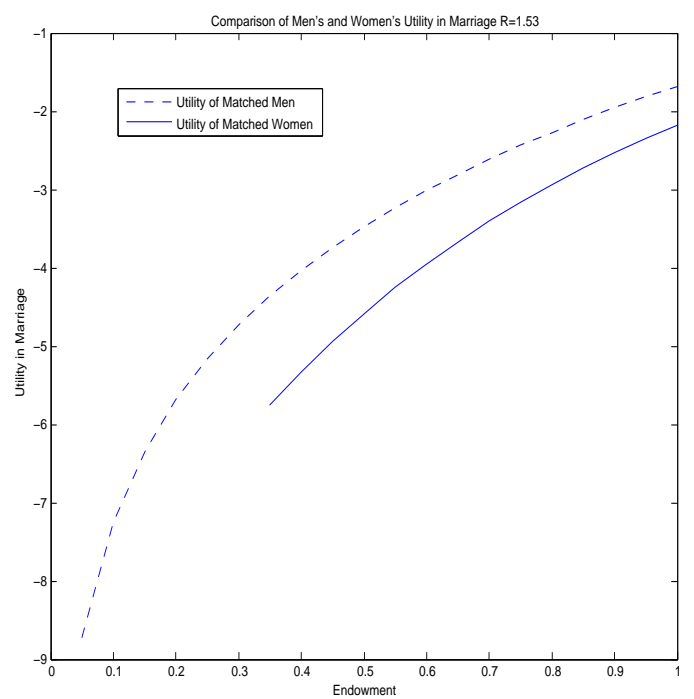

(d) Comparison of Matched Utilities 
Table 1: The Equilibrium with $r=1$

\begin{tabular}{|c|c|c|c|c|c|c|c|c|c|c|c|c|c|c|c|}
\hline & \multicolumn{5}{|c|}{$\begin{array}{c}\text { (a) } \\
r=1\end{array}$} & \multicolumn{5}{|c|}{$\begin{array}{c}\text { (b) } \\
r=1.25\end{array}$} & \multicolumn{5}{|c|}{$\begin{array}{c}(\mathrm{c}) \\
r=1.5\end{array}$} \\
\hline$y_{f}$ & $y_{m}$ & $\frac{y_{f}}{y_{f}+y_{m}}$ & $\frac{\omega_{f}}{\omega_{f}+\omega_{m}}$ & $\frac{c_{f}^{2}}{c_{f}^{2}+c_{m}^{2}}$ & $\frac{\operatorname{sur}_{f}}{t \text { sur }}$ & $y_{m}$ & $\frac{y_{f}}{y_{f}+y_{m}}$ & $\frac{\omega_{f}}{\omega_{f}+\omega_{m}}$ & $\frac{c_{f}^{2}}{c_{f}^{2}+c_{m}^{2}}$ & $\frac{\operatorname{sur}_{f}}{t \text { sur }}$ & $y_{m}$ & $\frac{y_{f}}{y_{f}+y_{m}}$ & $\frac{\omega_{f}}{\omega_{f}+\omega_{m}}$ & $\frac{c_{f}^{2}}{c_{f}^{2}+c_{m}^{2}}$ & $\frac{\operatorname{sur}_{f}}{t \text { sur }}$ \\
\hline 0.05 & 0.05 & 0.50 & 0.50 & 0.50 & 0.5 & n.m. & n.m. & n.m. & n.m. & n.m. & n.m. & n.m. & n.m. & n.m. & n.m. \\
\hline 0.10 & 0.10 & 0.50 & 0.50 & 0.50 & 0.5 & n.m. & n.m. & n.m. & n.m. & n.m. & n.m. & n.m. & n.m. & n.m. & n.m. \\
\hline 0.15 & 0.15 & 0.50 & 0.50 & 0.50 & 0.5 & n.m. & n.m. & n.m. & n.m. & n.m. & n.m. & n.m. & n.m. & n.m. & n.m. \\
\hline 0.20 & 0.20 & 0.50 & 0.50 & 0.50 & 0.5 & 0.00 & 1.00 & 1.00 & 1.00 & - & n.m. & n.m. & n.m. & n.m. & n.m. \\
\hline 0.25 & 0.25 & 0.50 & 0.50 & 0.50 & 0.50 & 0.0625 & 0.80 & 0.8346 & 0.7262 & 0.0451 & n.m. & n.m. & n.m. & n.m. & n.m. \\
\hline 0.30 & 0.30 & 0.50 & 0.50 & 0.50 & 0.50 & 0.125 & 0.7059 & 0.7464 & 0.6246 & 0.0979 & n.m. & n.m. & n.m. & n.m. & n.m. \\
\hline 0.35 & 0.35 & 0.50 & 0.50 & 0.50 & 0.50 & 0.1875 & 0.6512 & 0.6911 & 0.5699 & 0.1439 & 0.00 & 1.00 & 1.00 & 1.00 & - \\
\hline 0.40 & 0.40 & 0.50 & 0.50 & 0.50 & 0.50 & 0.25 & 0.6154 & 0.6534 & 0.539 & 27 & 69 & 0. & 0.8699 & 0.7743 & 0.0241 \\
\hline 0.45 & 0.45 & 0.50 & 0.50 & 0.50 & 0.50 & 0.3125 & 0.5902 & 0.6256 & 0.5194 & 0.2154 & 0.1538 & 0.7453 & 0.7869 & 0.6614 & 0.0575 \\
\hline 0.50 & 0.50 & 0.50 & 0.50 & 0.50 & 0.50 & 0.375 & 0.5714 & 0.6044 & 0.5054 & 0.2426 & 0.2308 & 0.6842 & 0.7287 & 0.5946 & 0.0912 \\
\hline 0.55 & 0.55 & 0.50 & 0.50 & 0.50 & 0.50 & 0.4375 & 0.557 & 0.5878 & 0.4954 & 0.2656 & 0.3077 & 0.6412 & 0.6858 & 0.552 & 0.1229 \\
\hline 0.60 & 0.60 & 0.50 & 0.50 & 0.50 & 0.50 & 0.50 & 0.5455 & 0.5743 & 0.4876 & 0.2852 & 0.3846 & 0.6094 & 0.6529 & 0.5225 & 0.1516 \\
\hline 0.65 & 0.65 & 0.50 & 0.50 & 0.50 & 0.50 & 0.5625 & 0.5361 & 0.5632 & 0.4819 & 0.3023 & 0.4615 & 0.5848 & 0.6266 & 0.5011 & 0.1775 \\
\hline 0.70 & 0.70 & 0.50 & 0.50 & 0.50 & 0.50 & 0.625 & 0.5283 & 0.5538 & 0.477 & 0.3171 & 0.5384 & 0.5652 & 0.6052 & 0.4854 & 0.2010 \\
\hline 0.75 & 0.75 & 0.50 & 0.50 & 0.50 & 0.50 & 0.6875 & 0.5217 & 0.5458 & 0.4731 & 0.3301 & 0.6154 & 0.5493 & 0.5876 & 0.4727 & 0.2217 \\
\hline 0.80 & 0.80 & 0.50 & 0.50 & 0.50 & 0.50 & 0.75 & 0.5161 & 0.539 & 0.4704 & 0.3417 & 0.6923 & 0.5361 & 0.5728 & 0.4626 & 0.2402 \\
\hline 0.85 & 0.85 & 0.50 & 0.50 & 0.50 & 0.50 & 0.8125 & 0.5113 & 0.5331 & 0.4679 & 0.3519 & 0.7692 & 0.525 & 0.56 & 0.4551 & 0.2572 \\
\hline 0.90 & 0.90 & 0.50 & 0.50 & 0.50 & 0.50 & 0.875 & 0.5070 & 0.5278 & 0.4654 & 0.3611 & 0.8462 & 0.5154 & 0.549 & 0.4484 & 0.2725 \\
\hline 0.95 & 0.95 & 0.50 & 0.50 & 0.50 & 0.50 & 0.9375 & 0.5033 & 0.5232 & 0.4638 & 0.3695 & 0.9231 & 0.5072 & 0.5394 & 0.4427 & 0.2861 \\
\hline 1.00 & 1.00 & 0.50 & 0.50 & 0.50 & 0.50 & 1.00 & 0.50 & 0.5189 & 0.4619 & 0.377 & 1.00 & 0.50 & 0.5308 & 0.4382 & 0.2989 \\
\hline
\end{tabular}

n.m. : not married

$t$ sur: total surplus 